\title{
Review on Advanced Health Monitoring Methods for Aero Gas Turbines using Model Based Methods and Artificial Intelligent Methods
}

\author{
Changduk Kong* \\ Dep. of Aerospace Engineering, Chosun University
}

\begin{abstract}
The aviation gas turbine is composed of many expensive and highly precise parts and operated in high pressure and temperature gas. When breakdown or performance deterioration occurs due to the hostile environment and component degradation, it severely influences the aircraft operation. Recently to minimize this problem the third generation of predictive maintenance known as condition based maintenance has been developed. This method not only monitors the engine condition and diagnoses the engine faults but also gives proper maintenance advice. Therefore it can maximize the availability and minimize the maintenance cost. The advanced gas turbine health monitoring method is classified into model based diagnosis (such as observers, parity equations, parameter estimation and Gas Path Analysis (GPA)) and soft computing diagnosis (such as expert system, fuzzy logic, Neural Networks (NNs) and Genetic Algorithms (GA)). The overview shows an introduction, advantages, and disadvantages of each advanced engine health monitoring method. In addition, some practical gas turbine health monitoring application examples using the GPA methods and the artificial intelligent methods including fuzzy logic, NNs and GA developed by the author are presented.
\end{abstract}

Key words: Advanced gas turbine health monitoring, model based method, artificial intelligent method, performance deterioration

\section{Introduction}

The aero gas turbine having expensive, highly precise and long lead parts is operated in a severe hostile environment of high pressure and temperature gas. Breakdown or deterioration of components or parts strongly influences the aircraft operation [1-5]. Recently third generation predictive maintenance based on engine operating condition has been developed instead of the second generation preventive maintenance.

It can not only monitor and diagnose the engine condition but also give the appropriate maintenance action. Therefore it maximizes the availability and minimizes the maintenance cost [1].

The advanced engine health condition monitoring method is classified into the model based method (such as observers, parity equations, parameter estimation and Gas Path Analysis
(GPA)) and the soft computing method (such as expert system, fuzzy logic, Neural Networks (NNs) and Genetic Algorithms (GA)) [6-7].

Among the model based diagnostic methods, the linear GPA method was first proposed by Urban in 1967 [8]. While GPA has been widely used it is severely limited to use in cases of a high level faults [6]. Therefore to improve this limitation the non-linear GPA method was developed by Escher [9]. This method can solve non-linearity by the repetition technique. However, this method does not manage the sensor noise and bias problem [6-7].

Among the soft computing diagnostic methods, the intelligent diagnostic methods such as fuzzy logic, NNs and GA have been developed to solve the problems of the model based diagnostic methods [1], [6-7]. In 1995, Patel et al. studied diagnostics using the SIMULINK model and NNs [10], In 1998, Zhou studied diagnostics using fuzzy logic and NNs
This is an Open Access article distributed under the terms of the Creative Commons Attribution Non-Commercial License (http://creativecommons.org/licenses/by$\mathrm{nc} / 3.0 /$ ) which permits unrestricted non-commercial use, distribution, and reproduction in any medium, provided the original work is properly cited. 
[11], and in 2000, Tayler studied diagnostics using GA [12]. However, Zedda pointed out that NNs training is typically performed in cases where the input-output relationship is already known and it is very difficult to provide any level of confidence on the results obtained through the use of NNs [13]. In 2005, Volponi et al. analyzed the recent status of the diagnostic system of the aerospace propulsion systems [14], and in 2010, Simon developed an on-board integral engine performance monitoring and diagnostic system [15]. The GA has some distinctive features compared with typical calculusbased optimization methods; i. e. no derivatives are needed so any-non-smooth function can be optimized, constraints can be dealt with penalty functions, global search is used to avoid becoming stuck in a local minimum, and probabilistic rather than deterministic transition rules are used to create the next generation of strings from the current generation [67], [16-17]. Recently, Kong et al. studied a diagnostic system considering the sensor noise and bias of a two spool turbofan engine using the GA method [18].

The engine health monitoring techniques using the model based method requires the performance simulation program. In order to simulate gas turbine performance, it is necessary that a condition, in which each engine must follow its own component characteristics, should be satisfied [19].

Generally, in order to simulate performance similar to that of a real engine, major component maps should be used through component rig tests. However, component maps of most commercial engines are not released even to the purchaser because those are treated by the manufacturer' as an important propriety. Therefore most research engineers, who are studying the performance simulation of the gas turbine, use scaled maps based on the design point from the known and limited component maps [21]. However, the scaling method is only available if it uses very similar maps to the real engine. If similar maps were not used to simulate the engine, the simulated performance may differ considerably from the real engine performance at off-design conditions [2023]. In order to overcome the above mentioned difficulties, Kong et al. proposed a map generation method called the system identification method using partially given operation performance data from the engine manufacturer; they could improve the traditional scaling methods by multiplying the scaling factors at the design point to off-design point data of the original performance maps [20]. However, this technique has a limitation on generation of component maps for the engine performance simulation at various operational conditions. In addition, Kong et al. recently proposed a new map generation method obtained by applying genetic algorithms to random test data or performance deck data. They therefore showed the possibility of composing the component maps from some random performance data [22].

The performance simulation is classified into the steady state performance simulation and the dynamic performance simulation. The performance simulation programs are used not only for precisely estimating the engine performance, but also for monitoring the engine condition and building the dynamic model of the engine controller. The DYNGEN was developed as a program for calculating the steady-state and transient performance of turbojet and turbofan engines using FORTRAN language by Seller et al. [24], and Fawke developed a simulation program of gas turbine dynamic behaviors [25] while Seldner et al. used a generalized simulation technique for turbojet engine system analysis [26]. Recently generalized computer programs have been developed for simulating the performance of various types of gas turbines as well as arbitrary gas turbines [27-29]. Kurzke has developed a commercial program GASTURB [21]. Kong et al. have developed the use of engine condition monitoring programs due to component performance degradations [3033].

\section{Advanced diagnostic methods}

\subsection{Gas Path Analysis (GPA) Method}

The GPA method first developed by Urban $[8,34]$ is used to evaluate the component based health condition using the performance simulation program.

If any effect of measurement uncertainty is neglected, for a given engine operating point the basic equation for gas turbine performance can be expressed as follows [1,35]:

$$
\vec{Z}=\mathrm{h}(\vec{X})
$$

where $\vec{Z}=\mathrm{R}^{\mathrm{M}}$ is the measurement vector and $\mathrm{M}$ is the number of measurements, $\vec{X}=\mathrm{R}^{\mathrm{M}}$ is the component parameter vector, $\mathrm{N}$ is the number of component parameters, and $\mathrm{h}$ is a vectorvalued function, usually non-linear.

It is provided by the performance simulation model.

$$
(X)=\mathrm{h}^{-1} \vec{Z}
$$

Equation (1) can be expanded in a Taylor series. Small, higher order terms of expansion can be neglected.

The deviation of engine component parameters can be calculated using a fault matrix (or diagnostic matrix) which is the inverse of the influence coefficient matrix $\mathrm{H}$ :

$$
\Delta X=H^{-1} * \Delta Z
$$

The inverse of the influence coefficient matrix is referred to as "Fault Coefficient Matrix" (FCM) [35]. 
Equation (3) is called as the governing equation of Linear GPA. The Linear GPA is clearly a very powerful tool for analyzing the health of gas turbines. However, it has a severe limitation whereby in many circumferences the level of error introduced by the assumption of the linear model can be of the same order of magnitude as the fault being analyzed [6].

One way of improving the accuracy is to try to solve the non-linear relationship between dependent and independent parameters with an iterative method such as the Newton-Raphson method [9].

The relationship between the engine measurement (dependent) parameter deviation vector and the component (independent) parameter vector described by Equation (3) is re-written as follows for convenience:

$$
\Delta X=H^{-1} * \Delta Z
$$

The corrections are then added to the solution vector:

$$
\vec{X}_{\text {new }}=\vec{X}_{\text {old }}+\Delta \vec{X}
$$

and the process is iterated to convergence. This iterative process, called the Non-linear GPA has the advantage of overcoming the problem whereby the changes in $\vec{X}$ need to be small. In other words, the process seeks to solve numerically the non-linear set of equations defined in Equation (1). Escher proposed a percentage of the change in the independent parameter as typically $66 \%$ to improve the accuracy in the iteration process [9].

Through each interval, the change in the independent parameter becomes increasingly smaller and the process can be stopped when the change in the independent parameter has reached a convergence criterion that suits the needs [36]:

$$
\Delta \vec{Z}_{\text {sum }}=\sum_{j}^{M}\left|\Delta Z_{\text {measj }}-\Delta Z_{\text {calj } j}\right|\langle\delta
$$

where $\mathrm{M}$ is the number of measurements, $\vec{Z}_{\text {meas }}$ is the actual deteriorated measured parameter vector, $\vec{Z}_{c a l}$ is the calculated deteriorated measured parameter vector that is based on the detected component parameter vector, $\Delta \vec{X}$ and $\delta$ is the convergence criteria.

Based on the GPA method, in 1987 Rolls-Royce developed a COMPASS diagnostic system [37], in 1991 Pratt \& Whitney developed the SHERLOCK diagnostic system [38], and in 1994 General Electric developed the TEMPER diagnostic system [39].

\subsection{Kalman Filter (KF) method}

The Kalman Filter (KF) is used to obtain a recursive solution to the linear filtering problem first developed by Kalman [40]. The KF is an optimal recursive data processing algorithm used to estimate the health of the engine components in the presence of measurement noise and sensor bias [41-43]. A KF processes all available measurement data and prior knowledge about the system to produce an estimate of the desired variables with the statistically minimized error. The KF based linear algorithm involves a prediction step and the correction step. The Kalman filters for the non-linear systems are the Extended Kalman Filter (EKF) and the iterated Extended Kalman Filter (IEKF).

\subsection{Neural Networks (NNs) method}

Work on the artificial neural network has been motivated from its inception by the recognition that the human brain computes data in an entirely different way to that of the conventional digital computer. A neural network can be defined as a massively parallel distributed processor made up of simple processing units, which has a natural propensity for storing experimental knowledge and making it available for use. Neural Networks (NNs) or Artificial Neural Net Works (ANNs) have been applied in aerospace propulsion diagnostics [44, 45].

The following definitions apply to the most commonly used neural network. The network is made of units called neurons, each performing a weighted sum of its own inputs. The sum is then passed through a function, the so called activation function, which is usually non-linear $[1,44,45$, 46]. The output of the $j$-th neuron is:

$$
y_{i}=\varphi\left(\sum_{i=0}^{n} w_{i j} x_{j}\right)
$$

where $\varphi_{j}$ is the activation function applied to the weighted sum of the inputs $x_{j}$. Interneuron connections called synapses or links characterized by weights ( $w_{i j}$ as in Equation (7)) are used to store the knowledge which is acquired by the network through a learning process, during which proper algorithms change the values of the weights. When training is over, the weights are fixed and the net can be used in the so called recall mode.

Neurons are usually grouped in layers depending on the type of architecture and learning algorithm. Normally, a neural network has an input layer, one or more hidden layers, and an output layer. A typical configuration of neural networks is shown in Fig. 1. The selection of neural network configuration is based on a specific application and previous experience.

Among the various neural algorithms, back propagation is one of the most common, simple and effective for training feed forward NNs $[1,47]$. The concept of the algorithm is illustrated in Fig. 2. 
The typical feed forward network, also named Multi-Layer Perceptron (MLP), comprises three layers: the input, hidden and output layer. Each layer is made of a set of neurons. For the hidden and output neurons the output or activation value is computed according to Equation (7). A bias contributes to the so-called net value (i.e. the weighted summation of inputs used as an argument of the activation function): $x_{0}$ is usually assumed to be equal to -1 .

Figure 1 shows a single hidden layer feed forward net with 8 input, 6 hidden and 4 output neurons. The arrows show the direction of the information flow. Biases are not represented.

The simplest way to train a feed forward network such as that shown in Fig. 1 is through a learning algorithm named back propagation. Data used for training are pairs of inputoutput vectors. Output vectors are also called targets as the objective of the training is to modify weights to force the net to reproduce them whenever presented with the corresponding input patterns. The main utilization of a net of this type is to carry out pattern recognition or, in mathematical terms, a multi-dimensional approximation. Training set vectors are used by the algorithm to modify the weights, whereas test set vectors are not involved in this process but are used to test the net generalization properties.

Feed-Forward Back-Propagation Neural Networks (FFBP

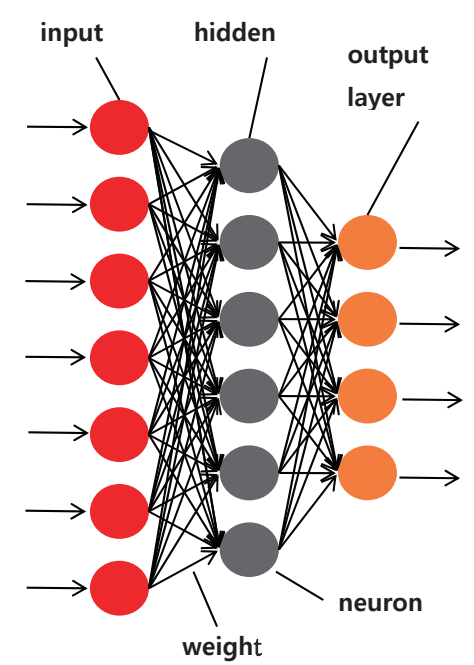

Fig. 1. A feed forward neural NNs

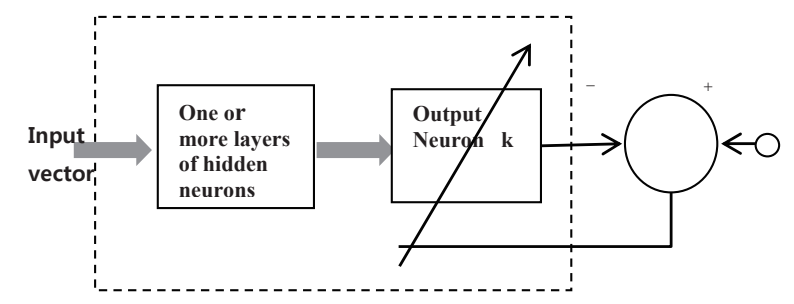

Fig. 2. Back propagation algorithm
NNs) are one of the NNs commonly used in gas turbine engine fault diagnostics. They can be used for fault detection, fault isolation and fault quantification.

The fault detection of a gas turbine engine can be carried out by training a neural network with faulty and no fault samples. An example of such a neural network is illustrated in Fig. 3 (1st stage) which has one input layer, one hidden layer and one output layer. Only one neuron appears in the output layer that is trained with either " 1 " indicating no fault in the engine and " 0 " indicating a faulty engine. Faulty gas turbine components can be isolated with FFBP NNs as shown in Fig. 3 (2nd stage) which has a similar configuration as that used in the fault detection except the number of neurons in the output layer. The number of neurons in the output layer equals the number of components to be detected.

Each of the neurons corresponds to one of the components to be detected and indicates a faulty component with " 0 " or no fault component with " 1 ". The neural network is trained with different types of samples. Multiple component fault detection is also possible. Gas turbine component faults can be quantified with FFBP NNs. Figure 3 (3rd stage) shows an example of a neural network for gas turbine fault quantification. It has a similar configuration to that used for fault isolation, where the number of neurons in the output layer is equal to the number of gas turbine component parameters, where the deviation of these parameters are to be quantified. The training samples are expressed with component parameter deviations and measurable parameter deviations. Once the neural network is trained and used in the application, it will provide the component parameter deviation for each new measurement set.

The single NN has limited capability for large and complicated problems, such as gas turbine diagnostics. Therefore, a nested NN system is necessary and an example of such a system is shown in Fig. 3. Different types of NNs can

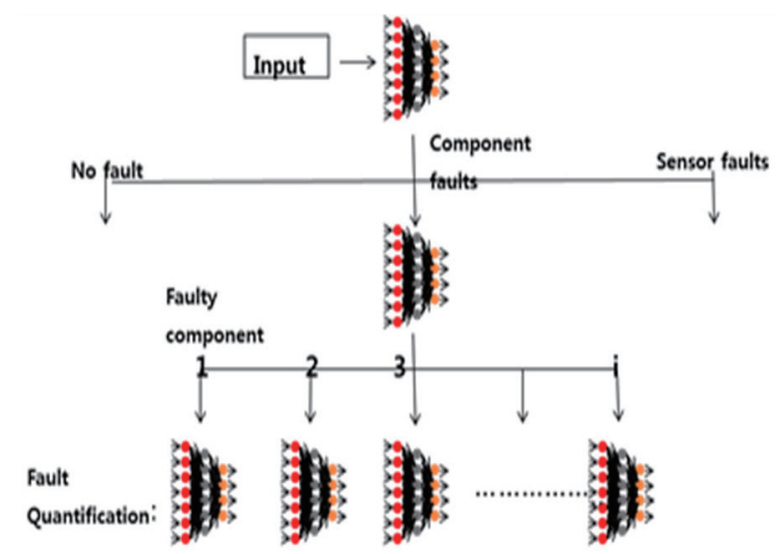

Fig. 3. Typical neural network based diagnostic system with 2 stages 
be used for gas turbine diagnostics purposes.

A number of gas turbine diagnostic programs using NNs have been developed [47-49].

Typical examples are listed below but are not discussed here except for the first program: feed forward-back propagation neural networks, Probabilistic neural networks, Self-organizing map (SOM), Learning vector quantization networks (LVQ), Counter propagation networks (CPN), Adaptive resonance theory networks (ART), Resource allocation networks (RAN), and Recurrent Cascade correlation neural networks (RCC) [6-7].

\subsection{Bayesian-Belief Network (BBN) method}

The BBN is a method used for fault identification of gas turbines based on formal probability theory. It is a system that integrates test measurements and gas path analysis program results with information regarding operational history and direct physical observation helping to acquire a cost effective diagnosis and using the value of information calculations [50-51].

\subsection{Genetic Algorithms (GA) method}

The GA is a stochastic algorithm of which search methods model some natural phenomena such as: genetic inheritance and Darwinian strive for survival. The idea behind genetic algorithms is to mimic nature [16].

The GA is applied as an effective optimization tool to obtain a set of component parameters that produce a set of predicted dependant parameters, through a nonlinear gas turbine model that leads to predictions that best match the measurements [6-7].

In the presence of measurement noise and bias, the following relationship for gas turbine component parameters and gas path measurement parameters would hold, as described previously [7]:

$$
\vec{Z}=h(\vec{x}, \vec{w})+\vec{v}+\vec{b}
$$

where: $\mathrm{h}($.$) is a vector valued function, v$ is the measurement noise vector, and $\vec{k}$ is the measurement bias vector.

Usually $\vec{v}$ is assumed to have a Gaussian probability density function (pdf) and moreover to have independent components. Therefore, the joint pdf is the product of the independent pdfs:

$$
P(v)=\frac{1}{(\sqrt{2 \pi})^{M}} \prod_{j=1}^{M}\left(\frac{1}{\sigma_{j}}\right) e^{-\frac{1}{2} \sum_{j=1}^{M}\left(\frac{v_{j}}{\sigma_{j}}\right)^{2}}
$$

where $\sigma_{j}$ is the standard deviation of the $\mathrm{j}$-th measurement.

The idea of gas turbines fault diagnosis with a genetic algorithm is shown in Fig. 4. With an initial estimation of the gas turbine component parameter vector $\vec{X}$, the engine model provides a predicted performance measurement vector $\vec{Z}$. An optimization approach is applied to minimize an objective function. A minimization of the objective is carried out iteratively until the best predicted engine component parameter vector $\vec{X}$ for real $\vec{X}$ is obtained.

The objective function is a measure of the difference between the real measurement vector $\vec{Z}$ and the predicted measurement vector $\vec{Z}$. The basic requirements for the objective function are as follows: It should be a measure of the consistency between actual and predicted measurements, measurement noise should be accounted for, measurement biases should be accounted for, its minimization should reduce the "smearing" effect, and evaluation of the function should not be too burdensome, considering computational factors.

A choice for the objective function would be, given a certain operating point:

$$
J(x)=\sum_{j=1}^{M} \frac{\left\lfloor z_{j}-h_{j}(\vec{x}, \vec{w})\right\rfloor}{z_{\text {odj }}(\vec{w}) \sigma_{j}}
$$

where ${ }^{{ }_{\text {odj }}}$ is the value of the $\mathrm{j}$-th measurement in the offdesign un-deteriorated condition.

Minimization of the objective function provides the maximum likelihood solution for the nonlinear problem.

Gas turbine sensor fault diagnostic is achieved with certain types of sensor redundancies.

The approach described previously for gas turbine component fault diagnostics with genetic algorithms can be modified to deal with measurement biases or sensor fault detection. The idea is based on the following criterion: the presence of a bias will introduce inconsistency between actual and predicted measurements.

The way the optimization-based diagnostic system handles measurement biases relies on the concept of analytical redundancy. If no bias affects the measurement, then the minimization of the object function expressed as Equation (10) can be performed.

The inconsistency due to a biased measurement would manifest itself with large values of the object function,

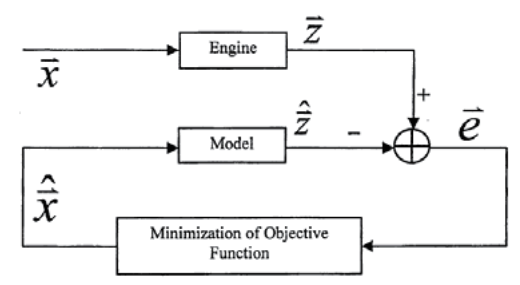

Fig.4. Non-linear model based diagnostic approach 
since no $\vec{X}$ can be found to correspond to the predicted measurements fitting sufficiently well with the real measurements. The problem can be overcome by elimination in the summation of the objective function of the Mbias terms corresponding to the biased measurements. Then the remaining terms are mutually consistent and the optimized function $\vec{X}$ will reach a low value. For the technique to apply, it is necessary that:

$$
\mathrm{M}-\text { Mbias }>\text { Nperf }+\mathrm{P}
$$

where $\mathrm{P}$ is the number of environment and power setting parameters and Nperf is the number of component performance parameters.

Some gas turbine diagnostic programs using GA have been developed [12, 18, 48].

\subsection{Expert Systems}

An expert system is a computer program that represents and reasons with knowledge of some specialist subject with a view to solving problems or giving advice [6, 7]. It is usually built by assembling a knowledge base which is then interpreted by an inference engine. An empty knowledge base comes from a program called a shell. The end user of the application interacts with the shell via the inference engine, which uses the knowledge input to the knowledge base to answer questions, solve problems, or offer advice. The configuration of a typical expert system is shown in Fig. 5.

Different expert systems have previously been developed, such as rule-based, model-based and case-based systems. The most popular types of expert systems used in gas turbine fault diagnostics is knowledge and rule based expert systems.

Typical examples of such systems are TEXMAS for Lycoming T53 engines, HELIX for twin engine gas turbine helicopter engines and SHERLOCK for helicopter engines, etc. [38].

Expert systems can also deal with problems involving uncertainty by using probability theory, fuzzy logic and belief functions.

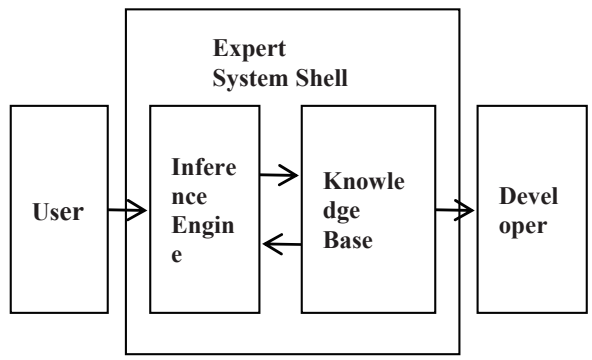

Fig. 5. Configuration of an expert system

\subsection{Fuzzy Logic}

Fuzzy logic is a method used to formalize the human capability of imprecise reasoning. Such reasoning represents the human ability to reason approximately and judge under uncertainty $[6,7,52]$. It provides a system of non-linear mapping from an input vector into a scalar output. The typical fuzzy logic system shown in Fig. 6 involves fuzzification, fuzzy inference and defuzzification by using a fuzzifier, an inference engine and a defuzzifier respectively. A fuzzifier maps crisp input numbers into fuzzy sets characterized by linguistic variables and membership functions. An inference engine maps fuzzy sets to fuzzy sets and determines the way in which the fuzzy sets are combined. A defuzzifier is sometimes used when crisp numbers are needed as an output of the fuzzy logic system. Fuzzy expert systems have previously been applied to gas turbine diagnostics.

A number of gas turbine diagnostic programs using Fuzzy Logic have been developed [53-55].

\section{Application examples of advanced diag- nostic methods}

Following practical gas turbine health monitoring application examples using the GPA methods and the artificial intelligent methods including fuzzy logic, the NNs and GA developed by the author are presented.

\subsection{Application example using Linear and Non-lin- ear GPA}

The selected engine for diagnostic application using GPA is the PT6-62 free-turbine type turboprop engine shown in Fig. 7 [56]. The maximum thermodynamic shaft horsepower is $1150 \mathrm{hp}$ at sea level and static standard condition, but the flat rated power is at $950 \mathrm{hp}$. The engine has a compressor with three axial stages and a single centrifugal stage, a reverse flow combustor, a single stage compressor turbine with cooled NGV and blades and an un-cooled two stage power turbine.

A program for steady state performance simulation and diagnostics of the turboprop engine (PT6A-62), which is a

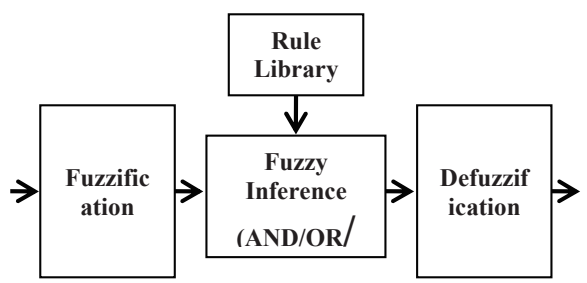

Fig. 6. Configuration of a rule-based fuzzy system 
power plant of the first indigenous military basic trainer KT-1 in the Republic of Korea, was developed [31].

In order to simulate the engine degradation effect, compressor fouling and turbine erosion are chosen, since they are likely to be the most common source of degradation in gas turbine engines. Compressor fouling leads to a decrease in compressor mass flow and isentropic efficiency, and turbine erosion leads to an increase in turbine mass flow and a decrease in isentropic efficiency.

In this study, the simultaneous multiple faults of the compressor, gas generator turbine and power turbine are assumed. The rotational speeds of the gas generator turbine and power turbine were assumed to be $100 \%$. The uninstalled condition at sea level, standard atmospheric and static condition were considered. For analyzing the performance degradation rate caused by compressor fouling and turbine corrosion, the parametric study with 3 cases is shown in Table 2 , and the parametric study for selection of the measurement parameters with 10 cases is shown in Table 3 .

The analysis results obtained by linear GPA were compared with those obtained by non-linear GPA. Furthermore nonlinear GPA analysis was carried out by using an iterative scheme, of which the performance degradation rate of independent parameters was divided into the same intervals, i.e., $\gamma=1$. This was compared with the analysis result obtained by Escher's scheme, i.e., $\gamma=0.66$ [9].

The analysis results for case 1 , case 2 , and case 3 are

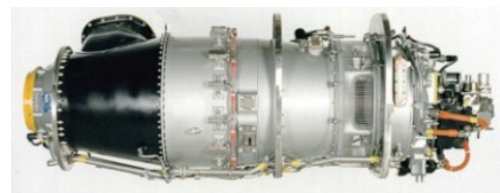

Fig. 7. PWC PT6A-62 turboprop engine

Table 1. Shows the reference data provided by the engine manufacturer [57].

\begin{tabular}{|c|c|}
\hline Variable & values \\
\hline \hline Atmospheric condition & S/L Static Standard \\
\hline Mass flow rate $(\mathrm{kg} / \mathrm{s})$ & 3.818 \\
\hline Compressor pressure ratio & 8.6 \\
\hline Fuel flow rate $(\mathrm{kg} / \mathrm{s})$ & 0.0818 \\
\hline Shaft horse power $(\mathrm{hp})$ & 1150 \\
\hline S.F.C $(\mathrm{kg} / \mathrm{kW} \cdot \mathrm{hr})$ & 0.3433 \\
\hline Nozzle throat area $(\mathrm{m} 2)$ & 0.058 \\
\hline Gas generator speed $(100 \% \mathrm{rpm})$ & 36200 \\
\hline Propeller speed $(100 \% \mathrm{rpm})$ & 2000 \\
\hline
\end{tabular}

shown in Fig. 8, respectively. In this investigation, it was found that nonlinear GPA with the same interval performance degradation rate of independent parameters is less effective than linear GPA. However the non-linear GPA method is considerably better than the linear GPA method when the performance degradation is large. In addition, it was found that results that are more accurate can be obtained if the larger number of the measurement parameters is selected.

However, when a specific set of measurement parameters is selected, the error can dramatically increase. Therefore if we can properly select the measurement parameters, an economic and reliable fault detection can be realized.

Table 2. Causes of performance deterioration and degradation rates

\begin{tabular}{|c|c|c|}
\hline Case & Source of deterioration & Degradation rates \\
\hline \multirow{3}{*}{ Case I } & Compressor fouling & $\begin{array}{c}\Gamma=-2 \% \\
\eta=-1 \%\end{array}$ \\
\hline & Comp. turbine erosion & $\begin{array}{c}\Gamma=+1 \% \\
\eta=-1 \%\end{array}$ \\
\hline & Power turbine erosion & $\begin{array}{c}\Gamma=+1 \% \\
\eta=-1 \%\end{array}$ \\
\hline \multirow{3}{*}{ Case II } & Compressor fouling & $\begin{array}{c}\Gamma=-3 \% \\
\eta=-2 \%\end{array}$ \\
\hline & Comp. turbine erosion & $\begin{array}{c}\Gamma=+2 \% \\
\eta=-2 \%\end{array}$ \\
\hline & Power turbine erosion & $\begin{array}{c}\Gamma=+2 \% \\
\eta=-2 \%\end{array}$ \\
\hline \multirow{3}{*}{ Case III } & Compressor fouling & $\begin{array}{c}\Gamma=-5 \% \\
\eta=-3 \%\end{array}$ \\
\hline & Comp. turbine erosion & $\begin{array}{c}\Gamma=+3 \% \\
\eta=-3 \%\end{array}$ \\
\hline & Power turbine erosion & $\begin{array}{c}\Gamma=+3 \% \\
\eta=-3 \%\end{array}$ \\
\hline
\end{tabular}

Table 3. Selection of dependent variables

\begin{tabular}{|c|c|c|c|c|c|c|c|c|c|c|}
\hline & 1 & 2 & 3 & 4 & 5 & 6 & 7 & 8 & 9 & 10 \\
\hline \hline SHP & 0 & 0 & 0 & 0 & 0 & & 0 & 0 & 0 & 0 \\
\hline MF & 0 & 0 & 0 & 0 & 0 & & & 0 & 0 & 0 \\
\hline P2 & 0 & 0 & 0 & & 0 & 0 & 0 & 0 & & 0 \\
\hline T2 & 0 & 0 & 0 & & 0 & 0 & 0 & & 0 & 0 \\
\hline P3 & 0 & & 0 & 0 & 0 & 0 & & 0 & & \\
\hline T3 & 0 & 0 & & 0 & 0 & & & & 0 & \\
\hline P4 & 0 & 0 & 0 & 0 & 0 & 0 & 0 & 0 & & 0 \\
\hline T4 & 0 & 0 & 0 & 0 & 0 & 0 & 0 & & 0 & 0 \\
\hline P5 & 0 & 0 & 0 & 0 & & 0 & 0 & 0 & & \\
\hline T5 & 0 & 0 & 0 & 0 & & 0 & 0 & & 0 & \\
\hline
\end{tabular}




\subsection{Application example using Fuzzy Logic and NNs}

An effective diagnostic system using the accurate base engine performance model of the PWC PT6A-67 turboprop engine, Fuzzy Logic and NNs has been proposed [58-59]. Figure 9 shows the flow of the proposed diagnostic system.

The target engine shown in Fig. 10 will be used for a long endurance UAV in the high altitude operation. This engine is composed of the 4-stages axial compressor and the 1-stage centrifugal compressor, the reverse annular vaporizing combustor, the 1-stage axial compressor turbine, and the 2 -stages axial free power turbine with constant speed control. Moreover it has a 2 stage reduction gear box, and the power is flat-rated to $1200 \mathrm{hp}$. Table 4 illustrates the design point performance data of this engine [58].

In order to obtain the measured performance parameter changes which are input data for the diagnostic system, the base engine performance model to estimate accurately the clean engine performance is firstly. Therefore, this work generates inverse component maps of the PWC PT6A-67
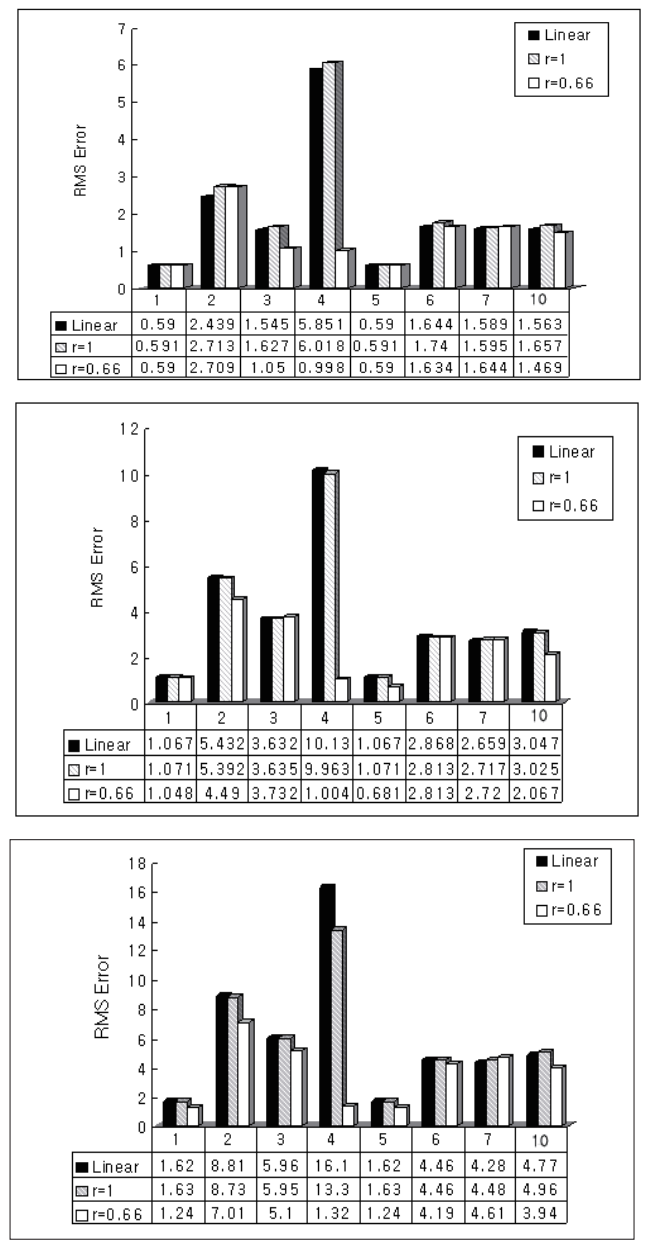

Fig. 8. RMS error in cases 1, 2, and 3 using Linear GPA and Non-linear GPA $(\gamma=1, \gamma=0.66)$ turboprop engine using limited performance deck data provided by the engine user and considering the high altitude engine behaviors. It then develops the base engine performance simulation program using the generated component maps shown in Fig. 11.

The proposed fault diagnostic program shown in Fig. 12 is composed of the Fuzzy Logic program for isolating faults from the monitored performance parameter changes and the Neural Network program for quantifying the isolated faults.

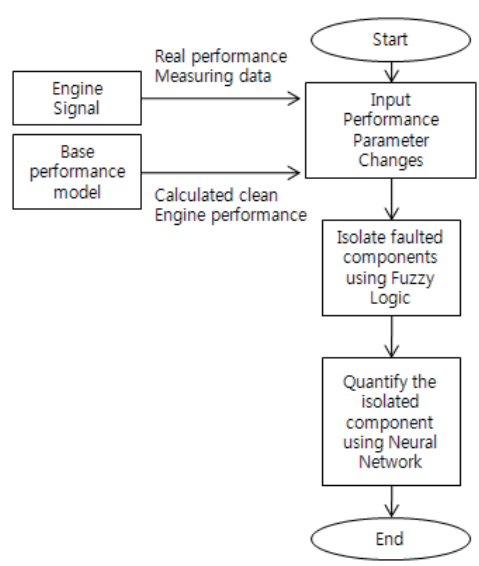

Fig. 9. Flowchart of Fuzzy-NNs diagnostic system

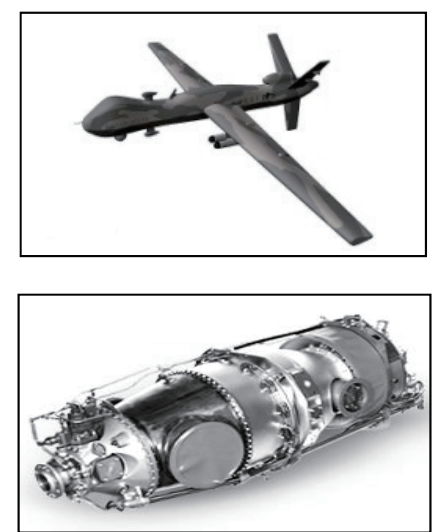

Fig. 10. Schematic view of medium altitude long endurance UAV and PT6A-67 turboprop engine

Table 4. Design point performance of PT6A-67 turboprop

\begin{tabular}{cc}
\hline Operation Conditions & Static Standard \\
\hline Gas Generation rpm & 39,000 \\
Power Turbine rpm & 29,894 \\
Propeller rpm & 1,700 \\
ITT (K) & 1,113 \\
Shaft Power (SHP) & 1,726 (Flat-rated to \\
\end{tabular}


Major component fault patterns are considered as single component fault patterns such as compressor fouling, compressor turbine erosion and power turbine erosion, and multiple component fault pattern combinations of two or three single component faults. Table 5 shows seven fault component pattern cases of the turboprop engine considered in this work.

Using the obtained measured performance parameter changes, the faulty components are isolated using Fuzzy Logic, and the isolated components are then quantified using the NNs learned by the learning data set. The verification is carried out by showing several test examples that show how well the proposed diagnostic system can detect component faults caused by intentionally implanted faults.

Through the following example, the proposed diagnostic program is verified. Measured parameter changes shown in Table 7 are obtained by implanted faults assumed as shown in Table 6 using the base engine model program. If the diagnostic program can identify the implanted faults with the measured parameter changes and trends, it is confirmed that this diagnostic program is verified.

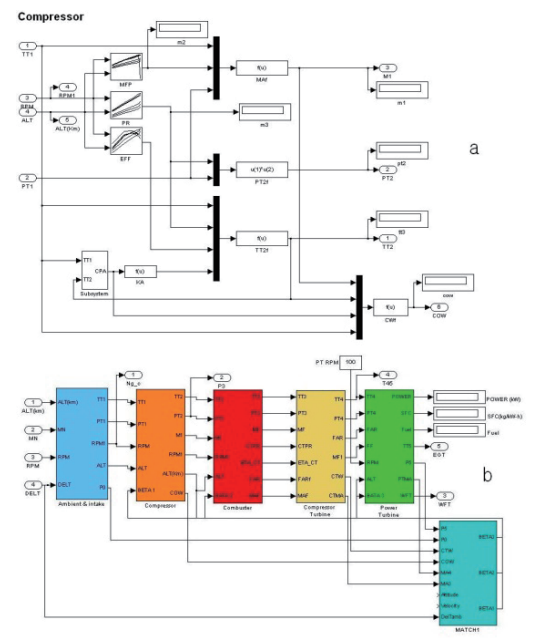

Fig. 11. Compressor Subsystem module, b : Base performance simulation program using SIMULINK

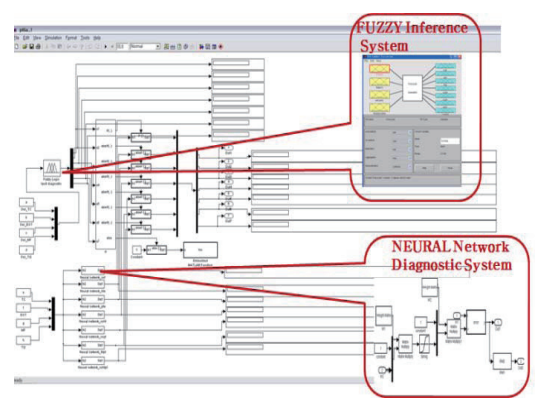

Fig. 12. Proposed fault diagnostic program using MATLAB/SIMULIN
Firstly, the measured parameter changes due to the 7 component fault pattern cases are entered as input data of the Fuzzy Inference System program. This Fuzzy Inference System isolates 7 component fault pattern cases from input data though fuzzyfication and defuzzycation using the previously generated Fuzzy rules. Table 8 shows that results of the faulted components isolated by Fuzzy Inference System are given as input to the Neural Network diagnostic program learned by the training data base. Here, if the largest value among the fault pattern results calculated by giving measured parameter changes using the Fuzzy Inference System approaches 1, the largest value becomes a possible component fault pattern. In Table 8, IFC1, i.e. input (or implanted) fault case 1 , has 0.51 at $\mathrm{OFC} 1$, i.e. output fault case 1 , which is the highest value among the 7 fault patterns; so this case has a high possibility of having a single fault with a contamination fault of the compressor. IFC7 has the highest value of 0.56 at pattern 7 ; therefore this case has a high

Table 5. Considered component fault pattern cases

\begin{tabular}{|c|c|}
\hline $\begin{array}{c}\text { Fault Cases } \\
\text { (FC) }\end{array}$ & Causes of faults \\
\hline $\mathrm{FC} 1$ & Compressor fouling \\
\hline $\mathrm{FC} 2$ & Compressor turbine erosion \\
\hline FC3 & Power Turbine Erosion \\
\hline FC4 & Comp. Fouling \& Comp. turbine erosion \\
\hline FC5 & Comp. Fouling \& Power turbine erosion \\
\hline FC6 & $\begin{array}{l}\text { Comp. turbine erosion \& Power turbine } \\
\text { erosion }\end{array}$ \\
\hline FC7 & $\begin{array}{l}\text { Comp. Fouling \& Comp. turbine erosion } \\
\& \text { Power turbine erosion }\end{array}$ \\
\hline
\end{tabular}

Table 6. Implanted fault values (IFV) of engine major components

\begin{tabular}{|c|c|c|c|c|c|c|}
\hline FC IFV & $\begin{array}{c}\text { COMA } \\
(\%)\end{array}$ & $\begin{array}{c}\text { COEF } \\
(\%)\end{array}$ & $\begin{array}{c}\text { HTMA } \\
(\%)\end{array}$ & $\begin{array}{c}\text { HTEF } \\
(\%)\end{array}$ & $\begin{array}{c}\text { PTMA } \\
(\%)\end{array}$ & $\begin{array}{c}\text { PTEF } \\
(\%)\end{array}$ \\
\hline FC1 & -5 & -3 & 0 & 0 & 0 & 0 \\
\hline FC2 & 0 & 0 & 5 & -3 & 0 & 0 \\
\hline FC3 & 0 & 0 & 0 & 0 & 5 & -3 \\
\hline FC4 & -4 & -2 & 4 & -2 & 0 & 0 \\
\hline FC5 & -4 & -2 & 0 & 0 & 4 & -2 \\
\hline FC6 & 0 & 0 & 4 & -2 & 4 & -2 \\
\hline FC7 & -5 & -5 & 5 & -5 & 4 & -4 \\
\hline
\end{tabular}


Table 7. Measured parameter changes due to implanted faults (\%)

\begin{tabular}{|c|c|c|c|c|}
\hline FC1 & $\Delta \mathrm{ITT}$ & $\Delta \mathrm{EGT}$ & $\Delta \mathrm{MF}$ & $\Delta \mathrm{TRQ}$ \\
\hline $\mathrm{FC} 2$ & 7.817 & 7.027 & 14.367 & 8.231 \\
\hline $\mathrm{FC} 3$ & -3.051 & -0.933 & -4.408 & -6.078 \\
\hline FC4 & 14.385 & 14.072 & 21.714 & 10.588 \\
\hline FC5 & 5.196 & 7.226 & 5.959 & -0.762 \\
\hline FC6 & 5.463 & 6.372 & 10.531 & 3.643 \\
\hline FC7 & 19.986 & 21.518 & 27.755 & 10.456 \\
\hline
\end{tabular}
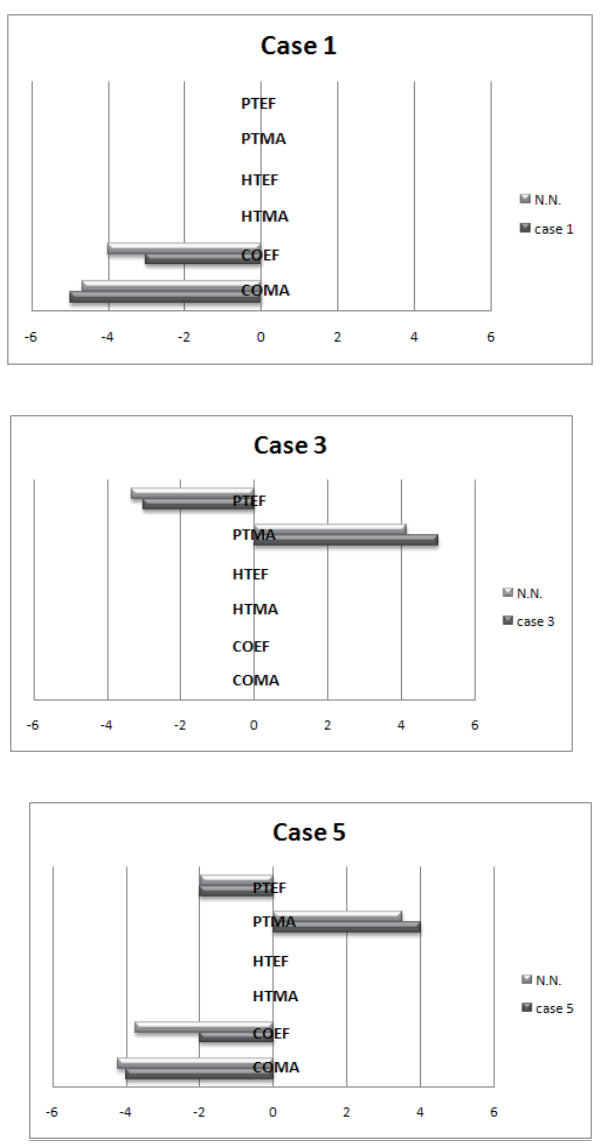

Table 8. Results of faulted components isolated by Fuzzy Inference System (IFC: Input fault cases, OFC: Output fault cases)

\begin{tabular}{|c|c|c|c|c|c|c|c|}
\hline IFC & 1 & 2 & 3 & 4 & 5 & 6 & 7 \\
\hline IFC1 & 0.51 & 0.09 & 0.08 & 0.08 & 0.43 & 0.26 & 0.09 \\
\hline IFC2 & 0.47 & 0.58 & 0.08 & 0.08 & 0.09 & 0.45 & 0.09 \\
\hline IFC3 & 0.09 & 0.09 & 0.68 & 0.08 & 0.09 & 0.08 & 0.09 \\
\hline IFC4 & 0.09 & 0.41 & 0.08 & 0.57 & 0.09 & 0.08 & 0.43 \\
\hline IFC5 & 0.40 & 0.09 & 0.20 & 0.08 & 0.56 & 0.08 & 0.09 \\
\hline IFC6 & 0.43 & 0.09 & 0.22 & 0.08 & 0.28 & 0.52 & 0.09 \\
\hline IFC7 & 0.45 & 0.27 & 0.08 & 0.45 & 0.28 & 0.47 & 0.56 \\
\hline
\end{tabular}
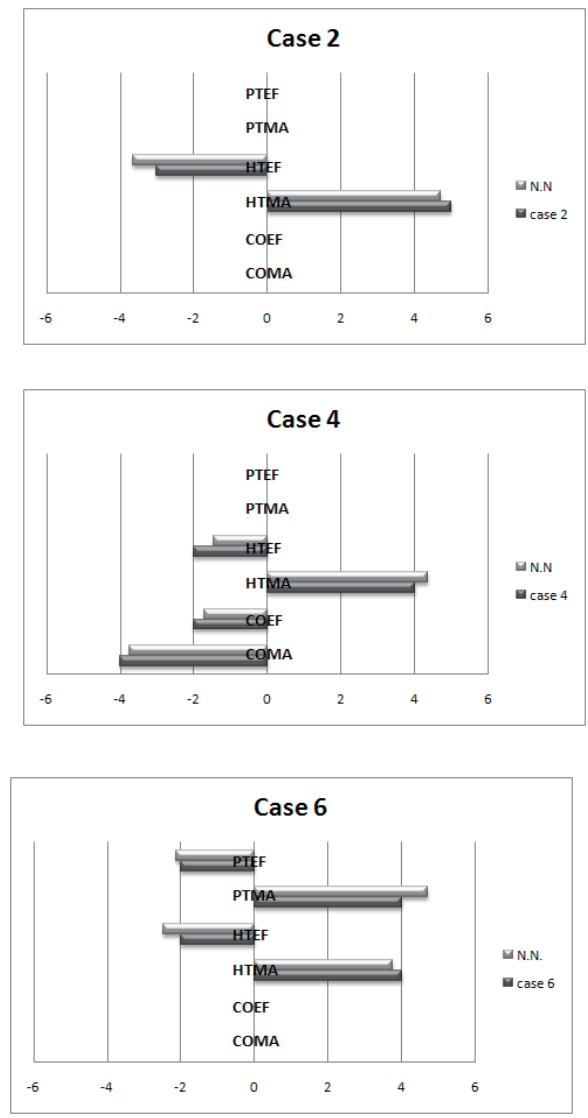

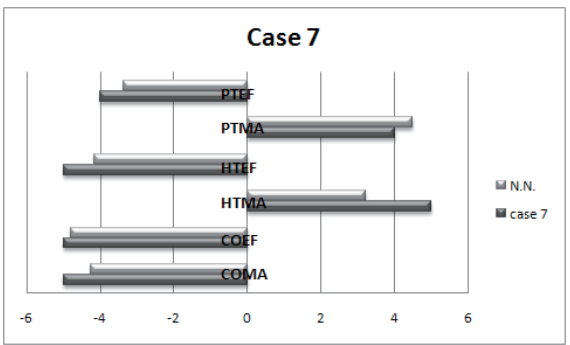

Fig. 13. Results of faulted components quantified by Neural Network diagnostic program 
possibility of being a multi fault case with a contamination fault of the compressor, erosion of compressor turbine and erosion of power turbine. As explained above, IFC2, IFC3, IFC4, IFC5, and IFC6 also have highest values at fault patterns $2,3,4,5$ and 6 , respectively.

Therefore, it is confirmed that the isolating fault patterns obtained from the fault monitoring program are the same as the implanted fault patterns.

In the next step, the measured performance parameter changes of the faulted components isolated by the FIS are given as input to the NN diagnostic program learned by the training data base.

Figure 13 shows the degraded characteristic values of the single and multiple faulted components found by the proposed NN diagnostic program. In the figures, cases $1 \sim 7$ refer to implanted degradations, and the N.N. refers to the identified degradations of each fault pattern by the NNs' diagnostic program.

As shown in Fig. 13, the proposed Fuzzy-NNs diagnostic program isolates exactly the faulted components for all of the 7 fault pattern cases, but the degradation results of the isolated faulted components quantified by the program have some errors. The error will be decreased by learning with more various case learning data and best selection of measured parameters

\subsection{Application example using GA}

The performance modeling engine for a fault diagnostic application example using GA [18] is a AE3007H 2 shaft mixed flow type high bypass turbofan engine manufactured by Rolls-Royce/Allison as shown in Fig. 14, and is composed of a 1 stage axial fan with a bypass ratio of 5 , a 14 stage axial high pressure compressor with a pressure ratio of 23 , a 2 stage axial high pressure turbine and a 3 stage axial low pressure turbine. The engine produces $36.9 \mathrm{KN}$ at take-off condition. Figure 1 shows the cut-down view of the AE3007H turbofan engine [60].

In order to diagnose the gas turbine engine, the implanted faults are first classified, and a set of the measuring

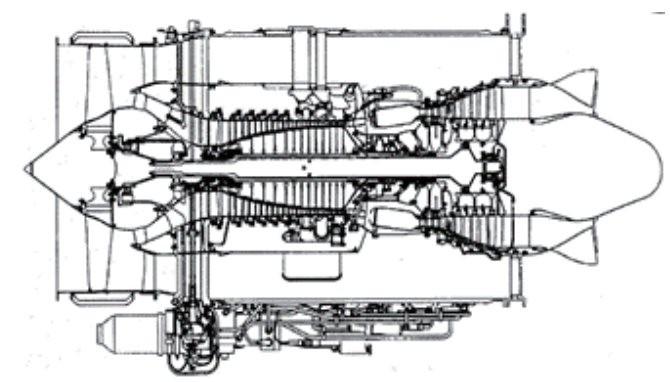

Fig. 14. Rolls-Royce/Allison AE3007H turbofan engine parameters to effectively detect the implanted faults are then selected. Depending on the numbers and types of measuring parameters, the precision of the diagnostic results is changed.

In order to evaluate the precision of the detected faults the following Root Mean Square (RMS) error formula is used.

In order to validate the condition monitoring analysis results by the linear GPA method, the non-linear GPA method and the GA method, known fault data must be needed. Either the real faulted engine data or the simulating faulted engine data are used. The use of real faulted engine data is preferred, but it is difficult to obtain all types of real faulted engine data as well as data without noise and bias. Therefore the simulating faulted engine data are generally used to verify the developing condition monitoring system. This work also uses the simulating faulted engine data.

In the condition monitoring analysis, the single faulted component cases and the multiple faulted component cases are considered with and without measuring noise and bias.

The number of implanted independent parameters must be less than the number of measuring parameters, and the considered faults are the compressor fouling case and the turbine erosion case. The degradation quantities of implanted faults for the analysis are shown in Table 9.

Compressor fouling results in reduced flow capacity and efficiency due to the reduction of flow area, and turbine erosion increases the nozzle area and decreases flow capacity and efficiency [2].

The selected measuring parameters are the inlet and outlet pressures and temperatures of the high pressure compressor, high pressure turbine, and the low pressure turbines and fuel flow. Here the pressure measuring parameter is related to the non-dimensional flow parameter, and the combination of pressure and temperature measuring parameters is related to the efficiency. The greater number of measuring parameters and the more precise diagnostic results are expected, but the measuring sensor error increase and the measuring cost increase [61-64].

Figure 15 (a) shows the diagnostic analysis results of single fault cases without sensor noise and biases. The analysis results using the linear GPA method have very low precision even in the case of low degradation, and the diagnostic RMS error of the high pressure compressor fouling case

Table 9. Implanted faults for compressor fouling and turbine erosion

\begin{tabular}{|l|c|c|c|}
\hline \multicolumn{2}{|c|}{ Compressor fouling } & \multicolumn{2}{c|}{ Turbine Erosion } \\
\hline Fan $\eta$ & -1.5 & HPT $\eta$ & -3 \\
\hline Fan $\Gamma$ & -2.0 & HPT $\Gamma$ & +4 \\
\hline HPC $\eta$ & -1.5 & LPT $\eta$ & -3 \\
\hline HPC $\Gamma$ & -2.0 & LPT $\Gamma$ & +4 \\
\hline
\end{tabular}


approaches about 2 . The analysis results using the nonlinear GPA method have more precision in all the single fault cases. However the analysis results using the linear GA method have a bit lower precision in all the single fault cases.

Figure 15(b) shows the diagnostic analysis results of single fault cases with sensor noise and biases to consider the real operating condition. According to the analysis results with noise and biases, the GA method has the lowest RMS error among the three methods. The linear GPA method has an RMS error of 9 in the fan fouling case, but the non-linear method has higher RMS errors than the linear GPA methods at other single fault cases. Moreover the GPA methods cannot detect the faults if the noise significantly increases.

Figure 15(c) shows the diagnostic analysis results of multiple fault cases without sensor noise and biases. According to the analysis results, the linear GPA method has very high RMS errors compared with the non-linear method and GA method; so it is found that the linear GPA method is very weak for use in the multiple fault cases. The non-linear GPA method has good results except for the fan and high pressure turbine multiple fault cases.

Figure 15(d) shows the diagnostic analysis results of multiple fault cases with sensor noise and biases. According to the analysis results with sensor noise and biases, the

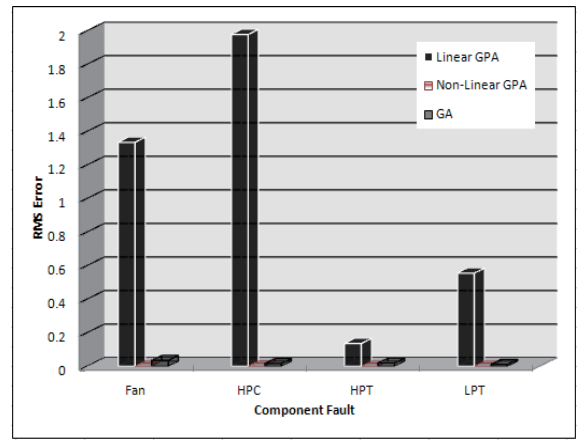

a. Single component faults without noise and biases

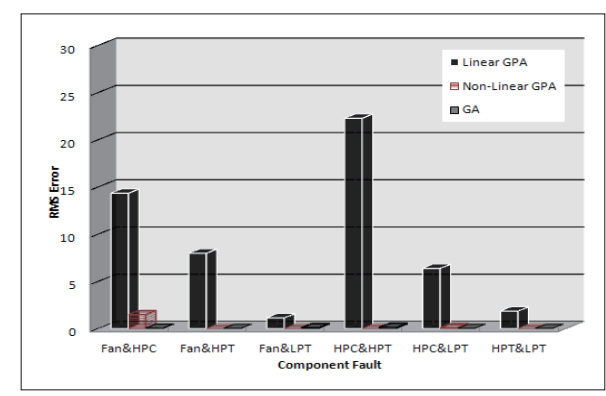

c. Multiple Component Faults without Noise and Biases
RMS errors of both the linear GPA method and the nonlinear GPA method increase, while the GA method has very low RMS errors compared to the GPA methods at all types of fault cases. This means that the GA method is a reliable acceptable diagnostic method for the condition monitoring of an AE3007E turbo fan engine.

\section{Concluding Remarks}

An overview of most advanced gas turbine health monitoring methods including GPA, KF, NNs, the BBN, GA, Expert System and Fuzzy Logic was presented. Thorough a number of practical gas turbine health monitoring application examples using the GPA and artificial intelligent methods including fuzzy logic, and the NNs and GA which were developed by the author, verifications and evaluations including the advantages and disadvantages of each diagnostic method were discussed.

The GPA method is a relatively simple artificial intelligent method, but it has low accuracy which is greatly influenced by measurement parameter selection. The nonlinear GPA improves the accuracy greatly, but computation time increases. However if noise or bias exists, the GPA can no

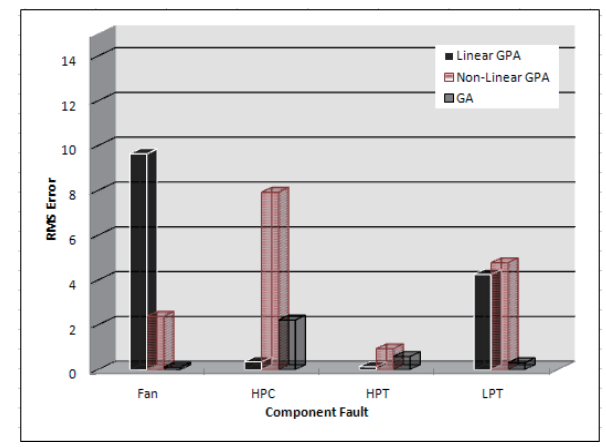

b. Single component faults with noise and biases

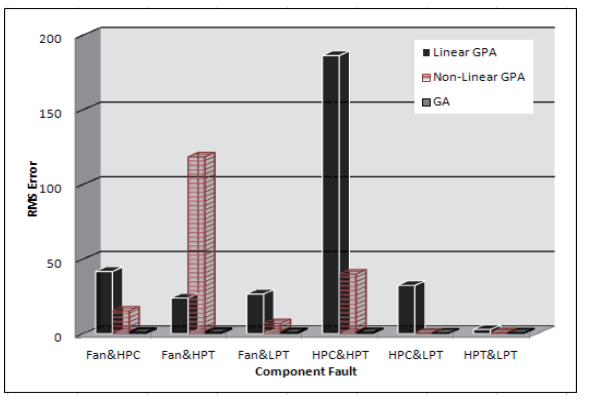

d. Multiple Component Faults with Noise and Biases

Fig. 15. Component Fault diagnostics with/without Noise and Biases 
longer be used to diagnose the engine faults. Moreover, the GPA cannot isolate clearly the component faults.

In order to solve the GPA's problems, Fuzzy-NNs are an effective artificial intelligent method. Fuzzy logic can isolate effectively the component faults and the NNs can quantify the isolated component's fault size. However, this method has a relatively complex structure and has a relatively long computation time. Moreover, it is problematic if noise or bias occurs.

The GA can accurately diagnose the component fault, even if both noise and bias occur. However, this method is greatly influenced by the engine simulation model and fitness factors, and requires a relatively long computation time and model complexity.

\section{References}

[1] Li, Y. G., “Gas Turbine Diagnostics", Lecture notes, Cranfield University, UK, 2002.

[2] Diakunchak, I. S., "Performance Deterioration in Industrial Gas Turbines", Journal of Engineering for Gas Turbines and Power, Vol. 114, No 2, 1992, pp.161-167.

[3] Lakshminarasimha, A.N., Boyce. M. P. and MeherHomji. C. B., "Modeling and analysis of gas turbine performance deterioration", Journal of Engineering for Gas Turbines and Power, Vol. 116, No.1, 1994, pp.46-52.

[4] Hamed, A., Tabakoff, W. and Singh, D., "Modeling of compressor performance deterioration due to erosion", International Journal of Rotating Machinery, Vol. 4, No. 4, 1998, pp.243-248.

[5] Tabakoff, W., Lakshminarasimha, N. and Pasin, M., "Simulation of compressor performance deterioration due to erosion", Journal of Turbo machinery, Vol. 112, No. 1, 1990, pp78-83.

[6] Marinai, L., Probert, D. and Singh, R., "Prospects for aero gas turbine diagnostics: A review", Applied Energy, Vol. 79, 2004, pp. 109-126.

[7] Li, Y. G., "Performance analysis based gas turbine diagnostics: A review", Proceedings of the Institute of Mechanical Engineering, Part A: Journal of Power and Energy, Vol. 216, No. A5, 2002.

[8] Urban, L.A., "Gas Turbine Engine Parameter Interrelationships", 2nd Edition, HS UAC, Windsor Locks, CT, 1969.

[9] Escher, P. C., "Pythia: An object-oriented Gas Path Analysis Computer Program for General Applications", PhD Thesis, Cranfield University, UK, 1995.

[10] Patel, V. C, et al, "Utilising a Simulink Gas Turbine Engine Model for Fault Diagnosis", Reprints of The IFAC
Symposium on Control of Power Plants and Power Systems, Cancum, Mexico, 1995, pp. 171-176.

[11] Zhou, J., "Intelligent Fault Diagnosis with Application to Gas Turbine Engines", PhD Thesis, The University of Sheffield, Sheffield, UK, 1998.

[12] Taylor, D. L., "Engine Health Diagnostics Using Multiple Operating Point Analysis and Genetic Algorithm Optimization", MSc Thesis, Cranfield University, Cranfield, UK, 2000.

[13] Zedda, M., "Gas Turbine Engine and Sensor Fault Diagnosis", PhD Thesis, Cranfield University, Cranfield,, UK, 2000.

[14] Volponi, A., "Enhanced Self-Tuning On-Board Real Time Model for Aircraft Engine Performance Health Tracking”, NASA CR-2008-215272, 2008.

[15] Simon, D. L., "An Integrated Architecture for Onboard Aircraft Engine Performance Trend Monitoring and Gas Path Fault Diagnostics,"Proceedings of The 2010 JANNAF Joint Subcommittee Meeting, Colorado Springs, May 3-7, 2010.

[16] Moon, B, L., “Genetic Algorithm”, Da Seong Pub.. Co., 2001.

[17] Chipperfield, A., Fleming, P., Pohlheim, H., and Fonseca, C., "Genetic Algorithm Toolbox for Use with MATLAB ver . 1.2”, University of Sheffield., 1995.

[18] Kong, C. D., Kang, M. C., and Park, G. L., "Study on Condition Monitoring of 2-Spool Turbofan Engine using Non-Linear Gas Path Analysis Method and Genetic Algorithms", International Journal of Materials, Mechanics and Manufacturing, Vol. 1, No. 2, 2013, pp. 214-220.

[19] Cohen, H., Rogers, G. F. C., and Saravanamutto, H. I. H., "Gas turbine Theory", 5th ed., Prince-Hall, Ehnglewood Cliffs, NJ, 2001.

[20] Kong, C. D., and Ki, J. Y., "A New Scaling Method for Component Maps of Gas Turbine Using System Identification", Journal of Engineering for Gas Turbines and Power, Vol. 125, No. 4, 2003, pp. 979-985.

[21] Kurzke, J., "Manual GASTURB 9.0 for Windows - A Program to Calculate Design and Off-design Performance of Gas Turbines”, Technical Report, 2001.

[22] Kong, C. D. and Ki, J. Y., "Components Map Generation of Gas Turbine Engine Using Genetic Algorithms and Engine Performance Deck Data", Journal of Engineering for Gas Turbines and Power, Vol. 129, No 2, 2007, pp.312-317.

[23] Li, Y.G., Pilidis, P. and Newby, M. A., "An Adaptation Approach for Gas Turbine Design-Point Performance Simulation", Journal of Engineering for Gas Turbines and Power, Vol. 128, No. 4, 2006, pp. 789-795.

[24] Sellers, J. F., and Daniele, C. J., "DYNGEN-A Program for Calculating Steady-State and Transient Performance of Turbojet and Turbofan Engines", NASA-TN D-7901, 1975. 
[25] Fawke, A J., "Digital Computer Simulation of Gas Turbine Dynamic Behavior", Ph.D. thesis, University of Bristol, UK, 1970.

[26] Seldner, K. et al., "Generalized Simulation Technique for Turbojet Engine System Analysis", NASA-TN-D-6610, 1972.

[27] Palmer, J. R., and Yan, C.-Z., “TURBOTRANS - A Programming Language for the Performance Simulation of Arbitrary Gas Turbine Engines With Arbitrary Control Systems", Int. J. Turbo Jet Engines, Vol. 2, No. 1, 1985, pp. 1928.

[28] Douglas, I, E., "Development of a Generalized Computer program for Gas Turbine Performance Simulation", PhD thesis, Cranfield University, Cranfield, UK, 1986.

[29] Schobeiri, M. T., Attia, M., and Lippke, C., “GETRAN: A Generic, Modularly, Structured Computer Code for Simulation of Dynamic Behavior of Aero-and Power Generation Gas Turbine Engines", Journal of Engineering for Gas Turbines and Power, Vol. 116, No. 3, 1994, pp. 483-494.

[30]Kong, C. D., and Chung, S. C., "Real Time Linear Simulation and Control for Small Aircraft Turbojet Engine", KSME Int. J., Vol, 13, No.9, 1999, pp. 656-666.

[31] Kong, C, D., and Ki, J Y., "Performance Simulation of Turboprop Engine for Basic Trainer”, ASME Paper No. 01-GT391, 2001.

[32] Kong, C. D. Park, J. H., Kang, M. C., "A Study on Transient Performance Characteristics of the Canard Rotor Wing Type Unmanned Aerial Vehicle Propulsion System During Flight Mode Transition", Journal of Engineering for Gas Turbines and Power, Vol. 128, No 3, 2006, pp.573-578.

[33] Kong, C. D. et al., "Study on Component Map Generation and Performance Simulation of 2-spool Separate Flow Type Turbofan Engine using SIMULINK", J. of KSPE, Vol. 17, No 1, 2013, pp. 70-79.

[34] Urban, L.A. "Parameter selection for multiple fault diagnostics of gas turbine engines”, AGARD CP-165, also ASME Paper 74-GT-62, Journal of Engineering for Power, Vol. 97, No. 2, 1975, pp. 225-230.

[35] Ogaji, S. O. T., Sampath S., Singh R. and Probert S. D., "Parameter selection for diagnosing a gas-turbine's performance-deterioration", Applied Energy, Vol. 73, No. 1, 2002, pp.25-46.

[36] Gatto. E. L., Li, Y. G. and Pilidis, P., "Gas turbine offdesign performance adaptation using a genetic algorithm", International 51st ASME Turbo Expo, Barcelona, Spain, 2006.

[37] Baswell, M.J, "COMPASS-Ground Based Engine Monitoring Program for General Application", SAETP-871734, 1987.

[38] Winston, H., at al, "Integrating Numeric and Symbolic
Processing for Gas Path Maintenance", AIAA-91-501, 1991.

[39] Doel, D.I., "TEMPER-A Gas-Path Analysis Tool for Commercial Jet Engines", Journal of Engineering for Gas Turbines and Power, Jan 1994, Vol. 116, No. 1, pp. 82-89.

[40] Kalman, R.E. and Bucy, R. S. "New results in linear filtering and prediction problems", ASME Transaction : Journal of Basic Engineering, Vol. 83, Series D, March 1961, pp. 95-108.

[41] Shet, K. C. and Rao, B. V., "An overview of the Kalman algorithm", International Journal of Electronics, Vol. 59, No. 6, 1985, pp. 657-665.

[42] Volponi, A. J., Depold, H., Ganguli, R. and Chen D., "The use of Kalman filter and neural network methodologies in gas turbine performance diagnostics: A comparative study", ASME 2000-GT-547, ASME TURBO EXPO 2000, Munich, Germany, May 2000.

[43] Walsh, G. and Bishop, G., "An introduction to the Kalman Filter", UNC-Chapel Hill, TR 95-041, 24 July 2006

[44] Dietz, W. E., Kiech, E. L. and Ali, M., "Jet and rocket engine fault diagnosis in real time", Journal of Neural Network Computing, Vol. 1, No. 1, 1989, pp. 5-18.

[45] Whitehead, B. A., Ferber, H. J. and Ali, M., "Neural Network Approach to space shuttle main engine health monitoring", AIAA/ASME/SAE/ASEE 26th Joint Propulsion Conference, July 1990, American Institute of Aeronautics and Astronautics, 1990, pp. 90-2559.

[46] Haykin, S., "Neural Networks: A Comprehensive Foundation", 2nd Edition, Prentice-Hall, Englewood Cliffs, NJ, 1999

[47] Bettocchi, R., Pinelli, M., Spina, P. R. and Venturini, M., "Artificial intelligence for the diagnostics of gas turbines Part 1: neural networks approach", Journal of Engineering for Gas Turbines and Power, Vol. 129, No. 3, 2007, pp.771-719.

[48] Suresh Sampath Riti Singh, "An Integrated Fault Diagnostics Model Using Genetic Algorithm and Neural Networks", Journal of Engineering for Gas Turbines and Power, Vol. 128, No 1, 2006, pp.49-56.

[49] Kanelopoulos, K., Stamatis, A., and Mathioudakis, K., "Incorporating Neural Networks Into Gas Turbine Performance Diagnostics”, ASME Paper, No. 97-GT-35, 1997.

[50] Palmer, C, A., "Combining Bayesian Belief Networks With Gas Path Analysis for Test Cell Diagnostics and Overhaul", ASME Paper, No. 98-GT-168, 1998.

[51] Kadamb, A., "Bayesian belief networks for aero gas turbine model and system fault isolation", MSc Thesis, Cranfield University, UK, 2003.

[52] Ross, T. J., "Fuzzy logic with engineering applications", Second Edition, John Wiley \& Sons, USA, 2004.

[53] Karvounis, G. and Frith, P., "Automated detection of engine health using hybrid model-based and fuzzy logic 
approach", ISABE 2003-1232, 16th International Symposium on air breathing engines, Cleveland, Ohio, 31 Aug.-5 Sept, 2003.

[54] Siu, C., Shen, Q. and Milne, R., "Reinforcing fuzzy rule-based diagnosis of turbo machines with case-based reasoning", IPS Press, Vol.12, No.2, 2008, pp.173-191.

[55] Ganguli, R., "Data rectification and detection of trend shifts in jet engine gas path measurement using median filters and fuzzy logic", Proceeding of ASME, Turbo Expo 2001, 2001-GT-0014, June 4-7, 2001, New Orleans, USA, 2001.

[56] Kong, C. D., and Ki, J. Y., “Optimal Measurement Selection of Turboprop Engine for Basic Trainer Using GPA Approach", ISABE-2001-1036, Proceedings of 15th ISABE, AIAA, Bangalore, India, 2001.

[57] Kong, C. D., "Propulsion System Integration of Turboprop Aircraft for Basic Trainer", ASME TUBO EXPO, 2000-GT-0010, 2000.

[58] Kong, C. D., and Lim, S.M., “Study on Fault Diagnostics of a Turboprop Engine Using Inverse Performance Model and Artificial Intelligent Method", ASME TURBO EXPO, GT2011-45336, 2011.

[59] Kong, C. D., Lim, S.M., and Kim, K.W., "Study on Practical Application of Turboprop Engine Condition Monitoring and Fault Diagnostic System Using Fuzzy-Neuro Algorithms", ASME TURBO EXPO, GT-2012-68158, 2012.

[60]Jane's Information Group, Jane's Aero Engine, issue 8, Coulsdon, Surrey, UK, 2000

[61] Zedda, M. and Singh, R.. "Gas turbine engine and sensor fault- diagnosis using optimization techniques", Joint of Propulsion \& Power, Vol. 18, No. 5, 2002, pp.1019-1025.

[62] Copper, W. S., "Use of optimal estimation theory, in particular the Kalman filter, in data analysis and signal processing", Review of scientific Instrumentation, Vol. 57, No. 11, November 1986, pp. 2862-2869.

[63] Volponi, A. J., "Sensor error compensation in engine performance diagnosticts", ASME, 94-GT-58, 1994

[64] Zedda, M., "Gas-turbine engine and sensor fault diagnosis", PhD Thesis, Cranfield, University, England, 1999. 